\title{
Nurses' experiences and perceptions of medication administration errors
}

\begin{tabular}{|c|c|c|}
\hline Newroz Ghazi Aziz* & Goran Aboobaker Osman* & Halmat Authman Rasheed* \\
\hline & Abstract & \\
\hline
\end{tabular}

Background and objective: Medication administration errors are the most common medical errors that happen in hospital settings. This study aimed to find out the most common types of medication administration errors done by the hospital nurses and identifying factors that lead to medication administration errors.

Methods: This cross-sectional survey was conducted across Erbil teaching hospitals over a period of three months from June 2016 to September 2016. A convenience sample of 250 nurses who were working in acute, subacute, and general wards and had direct contact with the medication administration were included in this study. Data were collected using a self-reported questionnaire.

Results: According to this study the most common types of medication errors were, noticing allergy after drugs administration and administering drugs at a wrong time. The highest leading factors of medication administration errors were illegible medication orders of the physicians, lack of adequate staffing and workload. High statistical differences were found between the frequency of medication administration errors with nurses' educational level, overall working experience, and nurses understanding language.

Conclusion: This study concluded that medication administration errors have multiple causes and types of errors are various.

Keywords: Medication administration error; Nurses' experience; Nurses' perspective.

\section{Introduction}

Medication administration errors (MAEs) are the most common medical error that happens in hospital settings. ${ }^{1}$ According to some observational studies, the incidence of MAEs varies between $10.5 \%$ to $44.6 \%$ of all administered doses. ${ }^{2-4}$ This figure indicates that errors occur in approximately one in five medications administered by nurses in healthcare settings. In developed countries like the United States of America, it has been estimated that approximately 7000 people die as a result of medication related-errors annually. ${ }^{5}$ The negative consequences of medication errors are not just affecting patients' health but may result in loss of confidence in the healthcare system, psychological distress among health care workers, prolonged hospital stay, and increase in treatment cost. ${ }^{6,7}$ Most of these errors happen as a result of human fault. ${ }^{8}$ In hospitals, different numbers of physicians, pharmacists, and nurses are involved in the process of medication preparation and administration. ${ }^{9}$ However, nurses are responsible for the biggest part of the medication process, which is the administration part. ${ }^{10}$ They are the gatekeepers who continually assess and evaluate patients' safety by maintaining active surveillance over the process of medication administration. ${ }^{11,12}$ Therefore, when errors happen nurses take the responsibility at a first place. Patient safety is a first goal-directed plan in many academics and healthcare organizations; therefore, a different strategic plan has been demonstrated to prevent the occurrence of MAEs. However, errors continue to occur. ${ }^{13}$ Various systemic and individual factors have been linked to

* Department of Adult Nursing, College of Nursing, Hawler Medical University, Erbil, Iraq. 
MAEs. ${ }^{11}$ Mahmood, Chaudhury, and Valente ${ }^{14}$ reported that lack of knowledge of health staff, work overload, the stress of healthcare professional and lack of staffing have a significant relationship to MAEs. Physical and environmental related factors like lack of medical equipment; lack of space for storing, preparing and documenting medications are related to MAEs as well. ${ }^{2}$ Lack of privacy in nurses' working area which resulted in interruption of health staff by patients, relatives, visitors and telephone calls during medication preparation and administration are other factors that have a relationship to MAEs. ${ }^{15}$ Poor communication between nurses and other healthcare providers such as physicians and pharmacists had a significant role to MAEs in a study done by $\mathrm{Kim}$, et al. $^{16}$ Failure in reporting the incidence and seriousness of medication errors in the healthcare setting reduces hospital safety and cause patients to be vulnerable to harm at any time. ${ }^{17}$ In Erbil, MAEs frequently happen, which require an immediate strategic plan to develop an interventional method that is capable of tackling medication safety issue effectively. In order, to implement strategic plan evidence about key factors contribute to MAEs, and common types of MAEs is needed. ${ }^{18,19}$ However, in Kurdistan region, reliable statistical data about MAEs is difficult to obtain. Basic information about causes and types of MAEs is not available because of lack of research; in addition, incidences of MAEs are usually not reported in teaching hospitals. Therefore, this study aimed to find common types of MAEs done by the study participants with identifying factors that lead to MAEs.

\section{Methods}

This descriptive cross-sectional survey aimed to provide information regarding nurses' experiences and perceptions of medication administration errors. The study was conducted across Erbil teaching hospitals, including Rizgary Teaching Hospital, Hawler Teaching Hospital, East
Emergency and Cardiac Center over a period of two months from June 2016 to August 2016. A convenience sample of 276 nurses who were working in acute, subacute, and general wards and had direct contact with the medication administration were asked to participate in this study. In total, 250 questionnaires were submitted to data analysis. Ethical consideration was obtained from the Scientific and Higher Education Committee of the College of Nursing, Hawler Medical University. Prior to data collection, the aim of the study was explained to the study participants, and they were assured that their participation would be kept anonymous and the provided data will be used for the research purpose only. The data were collected using a self-reported questionnaire which was consisted of three parts. First part was socio-demographic data developed by the study authors which included age, gender, marital status, level of education, working experience, working hours/shift, working shift, hospital ward which was categorized to three parts according to their acuity level; acute (RCU, CCU, ICU and neonatal care), subacute (Burn, Oncology, Dialysis center) and general ward (Outpatient department, Surgical ward, Neurology ward, Medical ward, Urology ward, Orthopedic ward, Catheterization care, Postpartum and Delivery room) and questions regarding the most comprehensible language by the study participants were included in the demographic data as well. The second part was common types of nurses' medication administration errors which consisted of 10 items. It was developed after reviewing relevant, and the third part was 26 statements regarding why medication administration errors happen obtained from a tool developed by Wakefield et al. ${ }^{20}$ called Medication Administration Errors (MAEs). The statements were divided into four groups; hospital-related factors, nurse-related factors, physician-related factors and medication with pharmacyrelated factors. The questionnaire was 
extensively reviewed by research (version 23) was used. Descriptive statistic committee at the college of nursing for its validity and relevancy then it was translated to the Kurdish language with minor changes in some words to make it more comprehensible for the study participants. The translation has been done by the study authors then reviewed by an assistant professor specialized in Kurdish and medical terminology. For data analysis, the statistical package for the social sciences was used to show the frequencies and percentage of independent and dependent variables, and to find the influence of nurses' characteristics on the frequency of MAEs, Chi square test was employed, and $P$ value set significant at 0.05 .

\section{Results}

Table 1 demonstrates that out of the 250 recruited nurses, more than half

Table 1: Study participants' sociodemographic characteristics.

\begin{tabular}{|c|c|c|}
\hline Characteristics & Frequency $\mathrm{N}=250$ & $(\%)$ \\
\hline \multicolumn{3}{|l|}{ Gender } \\
\hline Female & 128 & 51.2 \\
\hline \multicolumn{3}{|l|}{ Age group } \\
\hline 22---30 & 104 & 41.6 \\
\hline 31---39 & 93 & 37.2 \\
\hline 40----48 & 36 & 14.4 \\
\hline 49---56 & 17 & 6.8 \\
\hline \multicolumn{3}{|l|}{ Marital status } \\
\hline Single & 67 & 26.8 \\
\hline Married & 175 & 70.0 \\
\hline Divorced & 5 & 2.0 \\
\hline Widowed & 3 & 1.2 \\
\hline \multicolumn{3}{|l|}{ Level of education } \\
\hline Trained nurse & 13 & 5.2 \\
\hline High school nurse & 45 & 18.0 \\
\hline Diploma in nursing & 133 & 53.2 \\
\hline Bachelor in nursing & 55 & 22.0 \\
\hline Master in nursing & 4 & 1.6 \\
\hline \multicolumn{3}{|l|}{ Years of experience } \\
\hline 1---9 & 144 & 57.6 \\
\hline 10---18 & 61 & 24.4 \\
\hline 19---27 & 29 & 11.6 \\
\hline 28---36 & 16 & 6.4 \\
\hline \multicolumn{3}{|l|}{ Hospital ward } \\
\hline Acute & 78 & 31.2 \\
\hline Subacute & 35 & 14.0 \\
\hline General ward & 137 & 54.8 \\
\hline \multicolumn{3}{|l|}{ Working hours } \\
\hline 5---8 hr. & 175 & 70.0 \\
\hline 9---11hr. & 4 & 1.6 \\
\hline $12---14$ hr. & 71 & 28.4 \\
\hline \multicolumn{3}{|l|}{ Working shift } \\
\hline Morning & 119 & 47.6 \\
\hline Evening & 56 & 22.4 \\
\hline Night & 75 & 30.0 \\
\hline \multicolumn{3}{|c|}{ How many languages do you know? } \\
\hline Only Kurdish & 37 & 14.8 \\
\hline Kurdish and Arabic & 113 & 45.2 \\
\hline Kurdish, Arabic and English & 80 & 32.0 \\
\hline Kurdish and English & 20 & 8.0 \\
\hline
\end{tabular}


$(n=128 ; 51.2 \%)$ were female. The age of nurses ranged from 22 to 56 years with mean age of $33.91(\mathrm{SD}=7.6)$, and about two third of them were married $(n=175$; $70 \%)$. The greatest percentage $(53.2 \%)$ of nurses were holding a diploma in nursing, whereas only $5.2 \%$ were trained nurse and $18 \%$ were a high school nurse. The percentages of nurses who were holding bachelor and master degree in nursing were $22 \%$ and $1.6 \%$ respectively. More than half of the nurses $57.6 \%$ had working experience of one to nine years with a majority of them were working in general wards $(n=137,54.8 \%)$. Nearly half $(n=119,47.7 \%)$ of the study participants had a morning shift, and $70 \%$ of them were working five to eight hours per shift. The Kurdish and Arabic languages were the most understandable languages as it was stated by $45.2 \%$ of the study participants while the percentage of nurses who understood Kurdish, Arabic and English language was $32 \%$. A total of $14.8 \%$ understand only the Kurdish language, and $8 \%$ stated that the Kurdish and English languages are more understandable for them. Table 2 illustrates common types of MAEs. According to this study, the majority of nurses $58.4 \%$ reported that they have noticed allergy after they administered medications and about half of them $(47.2 \%)$ stated that they administered medications at wrong times. The percentage of nurses who had errors regarding wrong patients and wrong drugs was $30 \%$ equally while the omission of the dose and the wrong dose was $79 \%$ and $81 \%$ respectively. About one-quarter $(24.8 \%)$ reported that they administered medications at wrong routes and their errors regarding additional or unauthorized doses were $26.1 \%$. Fewer errors were made by the study participants regarding administering expired drugs and giving medications despite contraindications with a percentage of $14 \%$ and $14.4 \%$ respectively.

Table 2: Types of medication administration errors experienced by the nurses $(\mathrm{N}=250)$.

\begin{tabular}{lll}
\hline Types of medication administration errors & No. & $(\%)$ \\
\hline Wrong patient & 75 & 30.0 \\
Wrong drug & 75 & 30.0 \\
Omission of dose & 79 & 31.6 \\
Wrong dose & 81 & 32.4 \\
Wrong time & 118 & 47.2 \\
Expired drug & 35 & 14.0 \\
Wrong route & 62 & 24.8 \\
Additional/ unauthorized dose & 54 & 26.1 \\
Medicine given despite contra-indications & 36 & 14.4 \\
allergy to medication noted & 146 & 58.4 \\
\hline
\end{tabular}


Regarding factors associated with MAE (Table 3), the greatest number (219) of the study participants reported that "Physicians' medication orders are not legible" and "Lack of adequate staffing compared to the number of patients" are major factors of medication administration error with agreement rate $(87.6 \%),(87.2 \%)$ followed by "Workload" (agreement rate $\mathrm{n}=211,84.4 \%$ ), while the lowest reported factor was "Pharmacy does not prepare medications correctly" ( $n=84,33.6 \%)$. In general, the study showed that the nurses had high agreement rates across all types of factors that attribute to the occurrence of errors while administering medications.

Table 3: Nurses' perception of factors associated with medication administration error.

\begin{tabular}{lcc}
\hline Factors & Agreement rates \\
& No. & (\%) \\
\hline Hospital related factors: & 218 & 87.2 \\
Lack of adequate staffing compared to the number of patients. & 166 & 66.4 \\
Patient acuity levels. & 211 & 84.4 \\
Workload & 148 & 59.2 \\
Inadequate access to the policy of medication administration. & 120 & 48.0 \\
Lack of drug preparation facilities & 165 & 66.0 \\
Organizational routines & & \\
Nurses related factors: & 175 & 70.0 \\
Lack of knowledge about medications & 150 & 60.0 \\
Lack of understanding of how errors occur & 163 & 65.2 \\
Failure to adhere to policy and procedure documents & 120 & 48.0 \\
Distractions during preparation and administration of drug & 131 & 52.4 \\
Lack of documentation before and after administration & 194 & 77.6 \\
Stress & 106 & 42.4 \\
Poor communication between nurses & & \\
Physician related factors: & 219 & 87.6 \\
Physicians' medication orders are not legible & 205 & 82.0 \\
Physicians change orders frequently & 180 & 72.0 \\
Abbreviations are used instead of writing the orders out completely. & 160 & 64.0 \\
Verbal orders are used instead of written orders. & 170 & 68.0 \\
Poor communication between physicians and nurses & & \\
Medication and pharmacy related factors: & 120 & 48.0 \\
The names of many medications are similar & 132 & 52.8 \\
Different medications look alike & 144 & 57.6 \\
The packaging of many medications is similar & 132 & 52.8 \\
Medications are written under different language & 107 & 42.8 \\
Pharmacy delivers incorrect doses to the unit & 84 & 33.6 \\
Pharmacy does not prepare the medication correctly & 109 & 43.6 \\
Pharmacy does not label and document medication correctly. & 190 & 76.0 \\
\hline Poor communication between pharmacists and nurses & & \\
\hline
\end{tabular}


Table 4 , show no significant association between gender and MAEs $(P=0.156)$, while there was a highly significant association between level of education and MAEs $(P=0.001)$, this indicates, nurses who were holding bachelor and master degrees were less vulnerable to MAEs. The association between the overall years of experience and frequency of MAEs was also significant at $P=0.009$. Nurses with more working experience reported more MAEs. The language was also related to MAEs, and it has statistically reached significance at $P=0.004$, nurses who could understand Kurdish, Arabic, and English; and those who understood Kurdish and English were reported less MAEs.

\section{Discussion}

This study has examined nurse's experiences with the frequency of medication administration errors and nurses' perception of why errors happen during medication administration. In this study, 250 nurses were recruited from different department across Erbil teaching hospitals, Kurdistan region/ Iraq. The study found "noticing allergy after administering medication" was the most frequent error committed by the study participants. The percentage of this error is consistent with a study done by Morimoto et al., ${ }^{21,22}$ who also stated that this error usually happens as a result of not taking history regarding drug allergy, drug-drug interaction, not testing skin for drug sensitivity, administering the wrong dose, wrong drug and wrong technique. The percentage of administering drugs at a wrong time in this study was also high $(47.2 \%)$, this percentage is similar to a study done by Saleh et al., ${ }^{23}$ Agalu et al. ${ }^{24}$ and Biron. ${ }^{25}$ Wrong timing has been linked to lack of staffing in some studies ${ }^{26,27}$ in which they reported that because of inadequate staffing, nurses had to administer

Table 4: MAEs by demographic variables.

\begin{tabular}{llll}
\hline Variables & $\begin{array}{l}\text { MAEs } \\
\mathbf{N}(\%)\end{array}$ & $\begin{array}{l}\text { No MAEs } \\
\mathbf{N}(\%)\end{array}$ & $\boldsymbol{P}$ value \\
\hline Gender & & & \\
Male & & $11(9)$ & 0.156 \\
Female & $111(91)$ & $19(14.8)$ & \\
Level of education & $109(85.2)$ & & \\
Trained nurse & & $2(15.4)$ & \\
High school nurse & $11(84.6)$ & $2(4.4)$ & \\
Diploma in nursing & $43(95.6)$ & $5(3.8)$ & \\
Bch in nursing & $128(96.25)$ & $17(3.9)$ & \\
Master in nursing & $38(69.1)$ & $4(100)$ & \\
& $0(0.0)$ & & \\
Years of experience & & $24(16.7)$ & \\
1---9 & $120(83.3)$ & $5(8.2)$ & \\
10---18 & $56(91.8)$ & $0(0.0)$ & \\
19---27 & $29(100)$ & $1(6.3)$ & \\
28---36 & $15(93.8)$ & & \\
& & $3(8.1)$ & \\
Language & $34(91.9)$ & $6(5.3)$ & \\
Only Kurdish & $107(94.7)$ & $16(20)$ & \\
Kurdish \& Arabic & $64(80)$ & $5(25)$ & \\
Kurdish, Arabic \& English & $15(75)$ & & \\
Kurdish \& English & & & \\
\hline$P<0.05$ & & & \\
\hline
\end{tabular}


medication either earlier or later than the actual time of administration. This study has revealed four categories involved with MAEs; hospital related factors, nurse related factors, physician-related factors and medication with pharmacy related factors. Physician-related factors "illegibility of physician's medication order" was the most reported cause of MAEs. In a number of studies, nurses admitted that unclearness in written prescription order was responsible for MAEs. ${ }^{28-32}$ According to a study done in the USA unclearness in written prescriptions orders led 150 million pharmacists to call the responsible doctor for further information about the prescription. $^{33}$ Errors usually happen in prescriptions either when writing drug name, dose, frequency or route. ${ }^{28}$ Second and third major factors of MAEs according to this study were the lack of adequate staffing and workload "hospital related factors". In six studies nurse shortage was reported to be one of the main causes that might lead to MAEs. ${ }^{34-38}$ On the other hand, heavy staff workloads in three studies appeared to be a major leading factor to MAEs. ${ }^{39-41}$ Many studies have linked nurse shortage with increased workloads which in turn are both related MAEs. ${ }^{30,32}$ Stratton et al. ${ }^{29}$ and Dornan et al. ${ }^{42}$ stated that physical exhaustion and fatigue as a result of poor staffing and high workload are among the most frequently contributing factors to medication error. The analysis of the current study showed no statistically significant relationship between MAEs and gender. However, this data disagrees with a result found by Aboshaiqah ${ }^{43}$ who found a significant difference between the frequency of medication errors and gender in which the frequency of medication errors among female where higher than male. The result of this study demonstrates that nurses with higher education level had less MAEs. This result can be supported by a study done by Blegen et al. ${ }^{44}$ that found that higher education level is associated with better patient outcome. In their study, if a nurse had a bachelor degree or higher, the number of MAEs decreased significantly. ${ }^{44}$ However, this result does not indicate that high level educated nurses do not need theoretical and practical experience or workshop about delivering medication safely. Because according to a study done by Stratton et, al., ${ }^{29}$ the association between increased frequency of medication error and the high educational level was significantly high. When it comes to practice environment, nurses work gets influenced by the lack of staff, workload, hospital facility and nurses' relationship with physicians and pharmacist; therefore, having high certificates is not enough to avoid medical errors. Despite this result, there are other studies which found no correlation between MAEs and level of education. ${ }^{31,44}$ With regard to the study participants' overall years of experience, the frequency of medication errors among nurses who had more experience in clinical practice was significantly high compared to those with fewer years of practice. This finding is paralleled with a survey done by Sears ${ }^{45}$ and Kim et al. ${ }^{46}$ Vojir et al., ${ }^{47}$ in a survey stated that nurses with high years of experience have more ability to detect errors while administering medication, thus lead to a higher reporting rate. Another statistically significant association was found between nurses understanding language and frequency of MAEs. Those who were bilingual (Kurdish and English) and trilingual (Kurdish, Arabic and English) had less error. The Kurdish language is a first and official language in Kurdistan region. However, in the medical field and hospital, Kurdish, Arabic and English language are used. Therefore, nurses need to understand all these languages to avoid mistakes. Even though, more than half $(52.8 \%)$ of nurses in this study reported that "medications are written under different language" is one of a leading cause of MAEs. This factor has never been investigated in previous studies. The purpose of studying this factor in this survey was because of the majority of 
drugs used in Kurdistan's hospitals are imported from foreign countries, namely, India, Iran, Emirate, United Kingdom, Turkey, Syria, Saudi Arabia and Sweden. ${ }^{48}$ Therefore, nurses find difficulty in dealing with all these different languages. This study has several limitations. First, the sample size was small to be generalized for all nurses worked in selected hospitals in this study. Second, there was a reliance on self- reported questioner that would be difficult to prevent nurses to show their preferable image. Furthermore, the adverse effects of studied medication errors have not been investigated. Therefore, these limitations need to be considered in future research.

\section{Conclusion}

According to this study noticing allergy after drug administration and administering drugs at wrong times were the most frequent errors reported by the nurses. Regarding leading causes of MAEs, this study concluded that illegible medication orders of the physicians, lack of adequate staffing and workload were the highest leading factors to MAEs. Therefore, it can be concluded that MAEs have multiple causes and types of errors are various. In addition, high statistical differences were found between the frequency of MAEs with nurses' educational level, overall working experience, and the nurses 'most understanding language. In light of these results, Erbil teaching hospitals need to design an interventional program where all the staff are encouraged to report MAEs to know the frequency and severity of this issue whereby an action plan can be developed to overcome this issue.

\section{Competing interests}

The authors declare that they have no competing interests.

\section{References}

1. Wong IC, Wong LY, Cranswick NE. Minimising medication errors in children. Archives of Disease in Childhood. 2009; 94(2):161-4.

2. The Joint Commission. Preventing pediatric medication errors. SentinelEvent Alert 2008; 11(39):1-4.

3. Barker KN, Flynn EA, Pepper GA, Bates DW, Mikeal RL. Medication errors observed in 36 health care facilities. Arch Intern Med 2002; 162(16):1897-903.

4. van Gijssel-Wiersma DG, van den Bemt PM, Walenbergh-van Veen MC. Influence of computerised medication charts on medication errors in a hospital. Drug safety 2005; 28 (12):1119-29.

5. van den Bemt PM, Fijn $\mathrm{R}$, van der Voort $\mathrm{PH}$, Gossen AA, Egberts TC, Brouwers JR. Frequency and determinants of drug administration errors in the intensive care unit*. Critical care medicine 2002; 30(4):846-50.

6. Bootman JL, Wolcott J, Aspden P, Cronenwett LR, editors. Preventing Medication Errors: Quality Chasm Series. Washington, DC: National Academies Press; 2006 Dec 11.

7. Riaz MK, Hashmi FK, Bukhari NI, Riaz M, Hussain K. Occurrence of Medication Errors and Comparison of Manual and Computerized Prescription Systems in Public Sector Hospitals in Lahore, Pakistan. PloS One 2014; 9(8): e106080.

8. Tshiamo WB, Kgositau M, Ntsayagae E, Sabone $M B$. The role of nursing education in preventing medication errors in Botswana. IJANS 2015; 31(3)18-23.

9. Zhang J, Patel VL, Johnson TR. Medical error: Is the solution medical or cognitive? J Am Med Inform. Assoc 2002; 9(Supplement 6): S75-7.

10. Lisby M, Nielsen LP, Mainz J. Errors in the medication process: frequency, type, and potential clinical consequences. Int J Qual Health Care 2005; 17(1):15-22.

11. McLeod M, Barber N, Franklin BD. Facilitators and Barriers to Safe Medication Administration to Hospital Inpatients: A Mixed Methods Study of Nurses' Medication Administration Processes and Systems (the MAPS Study). PloS One 2015; 10 (6): e0128958.

12. McBride-Henry K, Foureur M. Medication administration errors: understanding the issues. Aust J Adv Nurs2006; 23 (3):33-41.

13. Wolf ZR. Medication errors and nursing responsibility. Holistic Nursing Practice 1989; 4(1):8-17.

14. Howell AM, Burns EM, Bouras G, Donaldson LJ, Athanasiou T. Can Patient Safety Incident Reports Be Used to Compare Hospital Safety? Results from a Quantitative Analysis of the English National Reporting and Learning System Data. PLoS One 2015; 10(12): e0144107.

15. Mahmood A, Chaudhury $H$, Valente $M$. Nurses' perceptions of how physical environment affects medication errors in acute care settings. Applied Nursing Research 2011; 24 (4):229-37. 
16. Willey C, Redding C, Stafford J, Garfield F, Geletko S, Flanigan T, et al. Stages of change for adherence with medication regimens for chronic disease: Development and validation of a measure. Clin Ther 2000; 22(7):858-71.

17. Kim KS, Kwon SH, Kim JA, Cho S. Nurses' perceptions of medication errors and their contributing factors in South Korea. J Nurs Manag 2011; 19(3):346-53.

18. Millenson ML. The silence. Health Affairs 2003; 22(2):103-12.

19. Bates DW. Mountains in the clouds: patient safety research. Qual Saf Health Care2008; 17(3):156-7.

20. Steven A, Magnusson C, Smith $P$, Pearson PH. Patient safety in nursing education: contexts, tensions and feeling safe to learn. Nurse Educ Today 2014; 34(2):277-84

21. Wakefield DS, Wakefield BJ, Uden-Holman T, Blegen MA. Perceived barriers in reporting medication administration errors. Best Pract Benchmarking Healthc1995; 1(4):191-7.

22. Morimoto T., Gandhi, T.K., Seger, A.C., Hsieh, T.C. Bates, D.W. Adverse drug events and medication errors: detection and classification methods. Qual Saf Health Care 2004; 13(4):30614.

23. Kopp BJ, Erstad BL, Allen ME, Theodorou AA Priestley G. "Medication errors and adverse drug events in an intensive care unit: Direct observation approach for detection", Crit Care Med 2006; 34(2):415-25.

24. Saleh AM, Awadalla NJ, El-masri YM, Sleem WF. Impacts of nurses' circadian rhythm sleep disorders, fatigue, and depression on medication administration errors. Egypt $\mathrm{J}$ Chest Dis Tuberc 2014; 63(1):145-53

25. Agalu A, Ayele Y, Bedada W, Woldie M. Medication administration errors in an intensive care unit in Ethiopia. Int Arch Med 2012 ;5(1):15.

26. Biron A. Medication administration complexity, work interruptions, and nurses' workload as predictors of medication administration errors. Library and Archives Canada $=$ Bibliothèque et Archives Canada; 2010.

27. Balas MC, Scott LD, Rogers AE. Frequency and type of errors and near errors reported by critical care nurses. Can J Nurs Res 2006; 38(2):24-41.

28. Chua SS, Chua HM, Omar A. Drug administration errors in paediatrics wards: a direct observation approach. Eur J Paediatr 2010; 169(5):603-11.

29. Jones JH, Treiber L. When the 5 rights go wrong: medication errors from the nursing perspective. J Nurs Care Qual 2010; 25(3):240-7.

30. Stratton KM, Blegen MA, Pepper G, Vaughn T. Reporting of medication errors by pediatric nurses. J Pediatr Nurs 2004; 19(6):385-92.

31. Mahmood A, Chaudhury H, Valente M. Nurses' perceptions of how physical environment affects medication errors in acute care settings.
Appl Nurs Res 2011; 24(4):229-37.

32. Mayo AM, Duncan D. Nurse perceptions of medication errors: what we need to know for patient safety. J Nurs Care Qual 2004; 19(3):209 -17 .

33. Petrova E. Nurses' perceptions of medication errors in Malta. Nurs Stand 2010; 24(33):41-8.

34. Karavasiliadou S, Athanasakis E. An inside look into the factors contributing to medication errors in the clinical nursing practice. Health Sci J 2014; 8(1):32-44.

35. Treiber LA, Jones JH. Devastatingly human: an analysis of registered nurses' medication error accounts. Qual Health Res2010; 20(10):132742.

36. Treiber LA, Jones JH. Medication errors, routines, and differences between peri operative and non-perioperative nurses. AORN J 2012; 96(3):285-94.

37. Hand K, Barber N. Nurses' attitudes and beliefs about medication errors in a UK hospital. Int $\mathrm{J}$ Pharm Prac 2000; (8)128-34.

38. Chua SS, Chua HM, Omar A. Drug administration errors in paediatrics wards: a direct observation approach. Eur J Paediatr 2010;169 (5):603-11.

39. Tang FI, Sheu SJ, Yu S, Wei IL, Chen CH. Nurses relate the contributing factors involved in medication errors. J Clin Nurs 2007; 16(3):44757.

40. Keers RN, Williams SD, Cooke J, Ashcroft DM. Prevalence and nature of medication administration errors in healthcare settings: a sys- tematic review of direct observational evidence. Ann Phar- Macother 2013; 47(2):23756.

41. Ozkan S, Kocaman G, Ozturk C, Seren S. Frequency of pediatric medication administration errors and contributing factors. J Nurs Care Qual 2011; 26(2):136-43.

42. Llewellyn RL, Gordon PC, Wheatcroft D, Butt AD, Lundgren AC, James MFM. Drug administration errors: Aprospective survey from three South African teaching hospitals. Anaesth Intensive Care 2009; 37(1):93-8.

43. Dornan $T$, Ashcroft $D$, Heathfield $H$, Lewis $P$, Miles J, Taylor D, et al. An in-depth investigation into causes of prescribing errors by foundation trainees in relation to their medical education: EQUIP study. London: General Medical Council; 2009. P. 1-215.

44. Aboshaiqah AE. Nurses' Perception of Medication Administration Errors. Am J Nurs Res 2014; 2(4):63-7.

45. Blegen MA, Goode CJ, Park SH, Vaughn T, Spetz J. Baccalaureate education in nursing and patient outcomes. J Nurs Adm 2013; 43(2):89_ 94.

46. Sears K, O'Brien-Pallas L, Stevens B, Murphy GT. The Relationship Between Nursing Experience and Education and the Occurrence of 
Reported Pediatric Medication Administration Errors. J Pediatr Nurs 2016; 31(4):e283-90.

47. Kim J, An K, Kim MK, Yoon SH. Nurses' perception of error reporting and patient safety culture in Korea. West J Nurs Res 2007; 29(7):827-44.

48. Vojir CP, Blegen MA, Vaughn T. Nursing staff as estimators of unit medication error reporting. Commun Nurs Res 2003; (36):202.

49. Zebari A. Modernization of drug distribution in Kurdistan: Is it possible to implement the Swedish drug distribution system in Kurdistan? 2013 (accessed August 20, 2016), available from http://www.divaportal.org/smash/record.jsf? pid=diva2\%3A618815\&dswid=4566 